\title{
Evaluation of Different Depth Injections of Reticulated Hyaluronic Acid Fillers with Different Concentration
}

\author{
Raffaele Rauso* \\ Assistant Professor, Department of Dentistry, University of Foggia, Italy
}

*Corresponding author: Raffaele Rauso, MD, Assistant Professor, Department of Dentistry, University of Foggia, Italy, E-mail: dr.raffaele.rauso@gmail.com

Received: 13 Nov, 2017 | Accepted: 26 Jan, 2018 | Published: 30 Jan, 2018

Citation: Rauso R (2018) Evaluation of Different Depth Injections of Reticulated Hyaluronic Acid Fillers with Different Concentration. J Clin Cosmet Dermatol 2(1): dx.doi.org/10.16966/2576-2826.125

Copyright: (C) 2018 Rauso R. This is an open-access article distributed under the terms of the Creative Commons Attribution License, which permits unrestricted use, distribution, and reproduction in any medium, provided the original author and source are credited.

\begin{abstract}
Background: Aging of the face is characterized by different phenomena happening at more or less the same time, these issues can be addressed both surgically and non surgically, with nonsurgical cosmetic medicine being exponentially more popular than surgical intervention. In this article, authors evaluate efficacy, safety and patient's satisfaction of a 3 different reticulated HA filler of $15 \mathrm{mg} / \mathrm{ml}$, $20 \mathrm{mg} / \mathrm{ml}$ and $25 \mathrm{mg} / \mathrm{ml}$ of non animal origin, produced via bacterial fermentation injected in different areas and different plane of the face.
\end{abstract}

Material and methods: Between January 2017 and June 2017, 25 patients ( 22 female and 3 male), ranging between 27 and 58 years old, seeking facial aesthetic medical treatments were enrolled in the present study. Three different HA filler formulation were used based on the anatomical area to treat: a $15 \mathrm{mg} / \mathrm{ml}$ formulation was used to treat crow's feet and glabella's wrinkle with superficial/intradermic injections, a $20 \mathrm{mg} / \mathrm{ml}$ nasolabial groove and peri-oral wrinkles filling with deep dermal plane injections, a $25 \mathrm{mg} / \mathrm{ml}$ to perform non surgical reshape of the nose, malar and chin augmentation with deep bolus injections, next or under the periosteum.

Results: Every patient was treated in a single stage injection. In 7 patients an ecchymosis occurred on site injection and was self resolved within 10 days, others complications did not occurred.

Patient's satisfaction form revealed a rating of $7,84 / 10$ after the first month, a 7,2/10 after 3 months and 6,16/10 after 6 months.

Conclusions: The HA fillers used in this paper showed a good profile of safety and a different lasting results based not only on the concentration of HA per vial but also due to site injection, deep versus superficial.

Keywords: Hyaluronic acid; Filler; Facial aesthetic

\section{Introduction}

Aging of the face is characterized by different phenomena happening at more or less the same time: Variable skin atrophic changes and wrinkle formation caused by genetic, actinic, and environmental factors; bone volume and facial fat loss; and skin sagging. These issues can be addressed both surgically and non surgically, with nonsurgical cosmetic medicine being exponentially more popular than surgical intervention $[1,2]$.

From an etiologic point of view, volume loss takes place mostly in the bony skeleton and fat compartments with predictable patterns $[3,4]$. The most common nonsurgical tools for volume correction are fillers, the main players of which are represented by hyaluronic acid gels; however, other fillers are on the market too. The concept of filling, blended with other nonsurgical techniques and based on surgical logics, allows the physician to get optimal results with minimal downtime and good longevity [5].

Fillers are traditionally characterized by rheology (i.e., physical response to applied forces). These properties, along with certain assumptions, have been used to predict how fillers will perform clinically. For instance, a filler with a higher G' value (i.e., firmer or more elastic) is assumed to resist tissue forces better and provide better lift than a filler with a lower $G$ ' value $[3,4,6-8]$. Although individual rheological properties are able to provide a framework for understanding some of the differences between fillers, direct translation of specific properties to clinical performance becomes difficult, as performance is influenced by a variety of filler characteristics (e.g., G', cohesivity, HA concentration, water uptake) and application (e.g., plane of injection, location, volume injected) [2].

In this article authors evaluate efficacy, safety and patient's satisfaction of a 3 different reticulated HA filler of $15 \mathrm{mg} / \mathrm{ml}$, $20 \mathrm{mg} / \mathrm{ml}$ and $25 \mathrm{mg} / \mathrm{ml}$ of non animal origin, produced via bacterial fermentation injected in different areas and different plane of the face. 


\section{Material and Methods}

Between January 2017 and June 2017, 25 patients (22 female and 3 male), ranging between 27 and 58 years old, seeking facial aesthetic medical treatments were enrolled in the present study. Exclusion criteria were represented by pregnancy, breast feeding, previous aesthetic medical treatments performed in the last year, systemic illness or metabolic disorders, etc.

Three different HA filler formulation were used based on the anatomical area to treat: a $15 \mathrm{mg} / \mathrm{ml}$ formulation was used to treat crows feet and glabella's wrinkles (Hyamira Soft, Apharm s.r.l., Arona, Italy) with superficial/intradermic injections, a $20 \mathrm{mg} / \mathrm{ml}$ nasolabial groove and peri-oral wrinkles filling (Hyamira Basic, Apharm s.r.l., Arona, Italy) with deep dermal plane injections, a $25 \mathrm{mg} / \mathrm{ml}$ to perform non surgical reshape of the nose, malar and chin augmentation (Hyamira forte, Apharm s.r.l., Arona, Italy) with deep bolus injections, next or under the periosteum.

Treated areas and the amount of HA injected is listed in table 1.

All the patients were treated after a careful clinical evaluation and after fulfilling the informed consent. All the patients were

Table 1: Anatomical area treated, number of vials used and improvement rate scale filled by the patients after 1, 3 and 6 months from the treatment

\begin{tabular}{|c|c|c|c|}
\hline $\begin{array}{c}\text { Treated area and } \\
\text { number of vials used }\end{array}$ & $\begin{array}{l}\text { Improvement } \\
\text { rate scale-1 } \\
\text { month }\end{array}$ & $\begin{array}{l}\text { Improvement } \\
\text { rate scale-3 } \\
\text { months }\end{array}$ & $\begin{array}{c}\text { Improvement } \\
\text { rate scale- } 6 \\
\text { months }\end{array}$ \\
\hline Lips, 1 vial & 8 & 7 & 6 \\
\hline Lips, 1 vial & 7 & 7 & 5 \\
\hline Lips, 1 vial & 8 & 7 & 6 \\
\hline Nasolabial groove, 1 vial & 8 & 7 & 6 \\
\hline Nasolabial groove, 1 vial & 8 & 7 & 6 \\
\hline Malar area, 2 vials & 10 & 9 & 7 \\
\hline Nasolabial groove, 1 vial & 8 & 7 & 6 \\
\hline Nose, 1 vial & 8 & 8 & 8 \\
\hline 2 Chin, 2 vials & 8 & 8 & 8 \\
\hline 1 Gabella, 1 vial & 8 & 8 & 6 \\
\hline 1 Gabella, 1 vial & 8 & 8 & 7 \\
\hline Crow's feet, 1 vial & 8 & 7 & 6 \\
\hline Nose, 1 vial & 9 & 9 & 9 \\
\hline Nasolabial groove, 1 vial & 7 & 6 & 5 \\
\hline Lips, 1 vial & 8 & 7 & 6 \\
\hline Nasolabial groove, 1 vial & 8 & 7 & 5 \\
\hline Malar area, 2 vials & 10 & 8 & 7 \\
\hline Nasolabial groove, 1 vial & 6 & 6 & 5 \\
\hline Nasolabial groove, 1 vial & 7 & 6 & 5 \\
\hline Malar area, 2 vials & 8 & 8 & 6 \\
\hline Nasolabial groove, 1 vial & 6 & 6 & 5 \\
\hline Nose, 1 vial & 9 & 9 & 9 \\
\hline Nasolabial groove, 1 vial & 7 & 6 & 5 \\
\hline Nasolabial groove, 1 vial & 7 & 6 & 5 \\
\hline Nasolabial groove, 1 vial & 7 & 6 & 5 \\
\hline
\end{tabular}

followed up at least for 6 months and at each post operative control (1 month, 3 months and 6 months after the injections) were asked to fulfill a satisfaction form.

The satisfaction form, given to each patients, asked for an evaluation from 0 to 10 , where 0 means "worsening compared to pre operation", 5 "no changes no worsening", and 10 "a great improvement reached".

\section{Injection techniques}

For each anatomical area a different HA filler formulation and a different plane of injection has been used; crow's feet and glabella were injected intradermally with a $15 \mathrm{mg} / \mathrm{ml}$ formulation with retrograde spaghetti-like or tear drop release; peri oral area and nasolabial groove were injected into the deep dermal plane with the same injective fashion as for glabella and crow's feet using a $20 \mathrm{mg} / \mathrm{ml} \mathrm{HA}$ filler; malar area, the chin and the nose where injected deeply next to the periosteum (for non surgical reshaping of the nose the injections were performed deeply, above the anterior nasal spine and above nasal bones) with bolus release, using a $25 \mathrm{mg} / \mathrm{ml} \mathrm{HA}$ filler.

\section{Results}

25 patients were treated with different reticulated HA filler formulations; every patients was treated in a single stage injection. In 7 patients an ecchymosis occurred on site injection (4 perioral and 3 malar) and was self resolved within 10 days, others complications did not occurred. Adverse events were clinically evaluated by the author.

Patient's satisfaction form revealed a rating of 7,84/10 after the first month, a 7,2/10 after 3 months and 6,16/10 after 6 months. Results under 5 were never recorded through the all 6 months of follow up; at the end of the 6 months follow up 9 patients evaluated 5 claiming no changes no worsening compared to the pre operation; 9 patients evaluated 6,3 patients evaluated 7, 2 patients evaluated 8 and 2 patients evaluated 9 affirming their appearance was greatly improved (Figures 1-3).

The highest patient's satisfaction was reported after non surgical nose reshaping, chin enhancement and some cases of malar augmentation, in all those clinical cases the injections where performed deeply next to the periosteum.

21 patients over 25 received $1 \mathrm{~mL}$ of HA injections, 4 over 25 received $2 \mathrm{~mL}$ ( 3 cases for malar augmentation and 1 for chin enhancement).

\section{Discussion}

With drastic increase in the popularity of nonsurgical techniques, it is very important to approach patients seeking enhancement and/or rejuvenation with a soft modality respectful of their anatomy and age. Physicians must be guided by the safety for the patient and by an aesthetic approach respectful of proportions. From a rheologic point of view, gels with high G' have more important lifting effect [9] and are more indicated in boluses over the supraperiosteal layer 

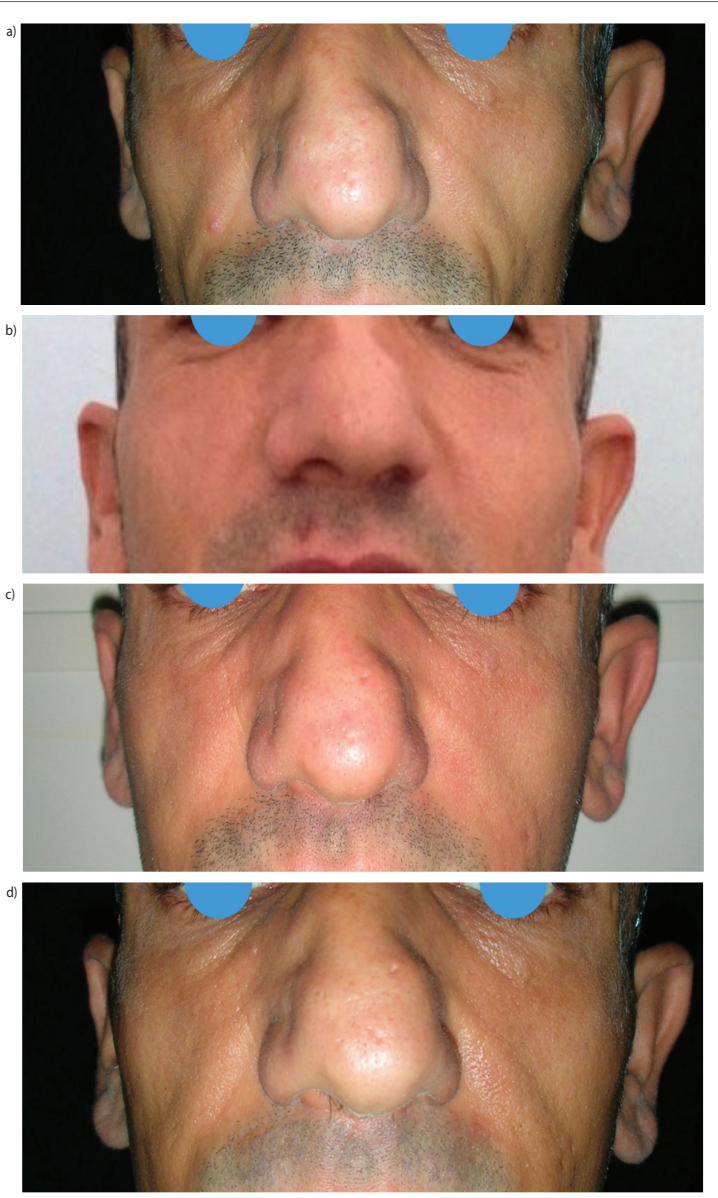

Figure 1: Pre operative (a), 1 month follow up (b), 3 months follow up (c), 6 months follow up after malar area augmentation, 1 vial per side of HA $25 \mathrm{mg} / \mathrm{ml}$
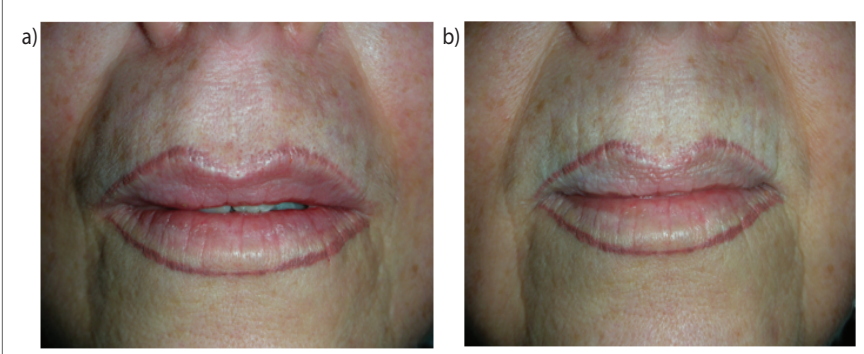

Figure 2: Pre operative (a) and 1 month (b) follow up after upper lip wrinkles restoration with 1 vial of $\mathrm{HA} 15 \mathrm{mg} / \mathrm{ml}$
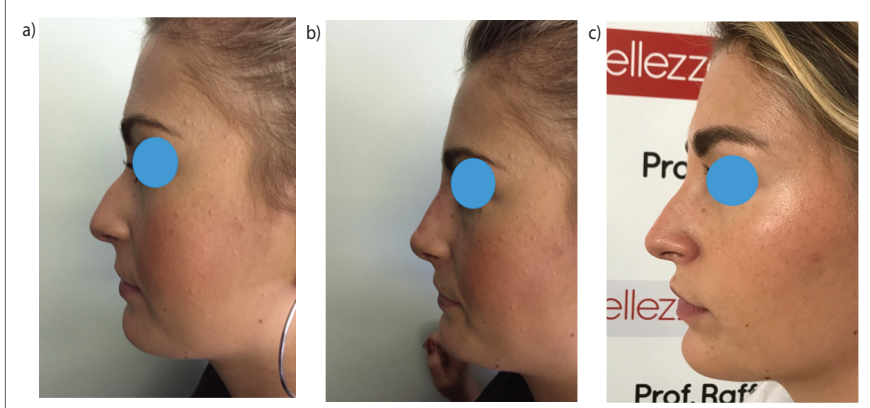

Figure 3: Pre operative, 1 month and 6 months follow up after non surgical remodeling of the nose with $\mathrm{HA} 25 \mathrm{mg} / \mathrm{ml}$ where they act as "pillars" to lift and support the tissues; on the other hand, gels with moderate G' and G" are more indicated to treat the subcutaneous tissue where they act like "bridges" to reconnect the pillars, thanks to their expander capacity [2]. Often, injecting the deep plane is sufficient to have good results in terms of natural volume and projection of tissues while the superficial plane allows for more tightening than volume.

Based on this issues, we injected the HA filler with the higher $\mathrm{G}^{\prime}$ and an higher HA concentration $(25 \mathrm{mg} / \mathrm{ml})$ deep to the periosteum, to perform non surgical remodeling of nose, chin and malar area; on the other hand, filler with a lower concentration of HA, 20 and $15 \mathrm{mg} / \mathrm{ml}$, were injected more superficial, just to restore superficial wrinkles such as glabella, perioral area, etc. (Figures 2a,2b).

A longer lasting result was observed when fillers were injected deep to the periosteum, this can be explained because the bony layer where trauma and deposition of the gel on the periosteum are able to activate the periosteal stem cells [10] with new tissue formation and almost a really long lasting effect. Reaching the bony layer is faster and easier with a needle, a very precise tool that gives the physiscian perfect control of the release of the gel: With an accurate anatomical study of the patient and a preoperative marking, needle injections target only the bony layer of the deep fat compartments avoiding all the septa where the vessels lie, allowing injections without bleeding [2]. On the other hand, when superficial wrinkles have to be treated, of course, superficial injections are needed and an HA filler with an high $\mathrm{G}^{\prime}$ is absolutely not recommended, however the results are not so long lasting as for the ones characterized by higher G' and injected deeply. The lasting differences between deep and superficial injections can be also explained because in the soft tissue there is an higher percentage of endogenous hyaluronidase compared to deep planes; of course an area with an higher percentage of hyaluronidase will resorb faster HA.

In the present study, complications such as nodules, blebs, foreign body reaction were never observed, this confirm a very high safety profile of the filler used.

\section{Conclusion}

The clinical trial carried out in this paper showed a good safety's profile of of the HA fillers used and a different lasting results based not only on the concentration of HA per vial but also due to site injection, deep versus superficial. From this study we can affirm that a filler with an higher concentration of HA can be safely injected deep to the periosteum giving long lasting results remodeling areas such as malar, nose and chin, on the other hand, lower HA concentration filler need to be injected more superficial and have a shorter lasting result but are essential to treat superficial wrinkles such as nasolabial groove, glabella and perioral wrinkles.

\section{Funding}

The author received no financial support for the research, authorship, and publication of this article. 


\section{References}

1. Few JW (2012) The beauty of blending: Surgical and nonsurgical synergy. QMP Plastic Surgery Pulse News 4: 1-4.

2. Salti G, Rauso R (2015) Facial rejuvenation with fillers: The dual plane technique. J Cutan Aesthet Surg 8: 127-133.

3. Shaw RB Jr, Kahn DM (2007) Aging of the midface bony elements: A three-dimensional computed tomographic study. Plast Reconstr Surg 119: 675-683.

4. Rohrich RJ, Pessa JE (2007) The fat compartments of the face: Anatomy and clinical implications for cosmetic surgery. Plast Reconstr Surg 119: 2219-2231.

5. Russo PR, Fundaro PS (2014) The invisible lifting. Florence: OEO 109-157.

6. Mendelson B, Wong $\mathrm{CH}$ (2012) Changes in the facial skeleton with aging: Implications and clinical applications in facial rejuvenation. Aesthetic Plast Surg 36: 753-760.
7. Sandoval SE, Cox JA, Koshy JC, Hatef DA, Hollier LH (2009) Facia fat compartments: A guide for filler placement. Semin Plast Surg 23: $283-287$

8. Ozdemir R, Kilinç H, Unlü RE, Uysal AC, Sensöz O, et al. (2002) Anatomicohistologic study of the retaining ligaments of the face and use in face lift: Retaining ligament correction and SMAS plication. Plast Reconstr Surg 110: 1134-1147.

9. Sundaram H, Cassuto D (2013) Byophisical characteristics of hyaluronic acid soft-tissue fillers and their relevance to aesthetic applications. Plast Reconstr Surg 132: s5-s21.

10. Mashiko T, Mori H, Kato H, Doi K, Kuno S, et al. (2013) Semipermant volumization by an absorbable filler: Onlay injection technique to the bone. Plast Reconstr Surg Glob Open 1: e4-e14. 